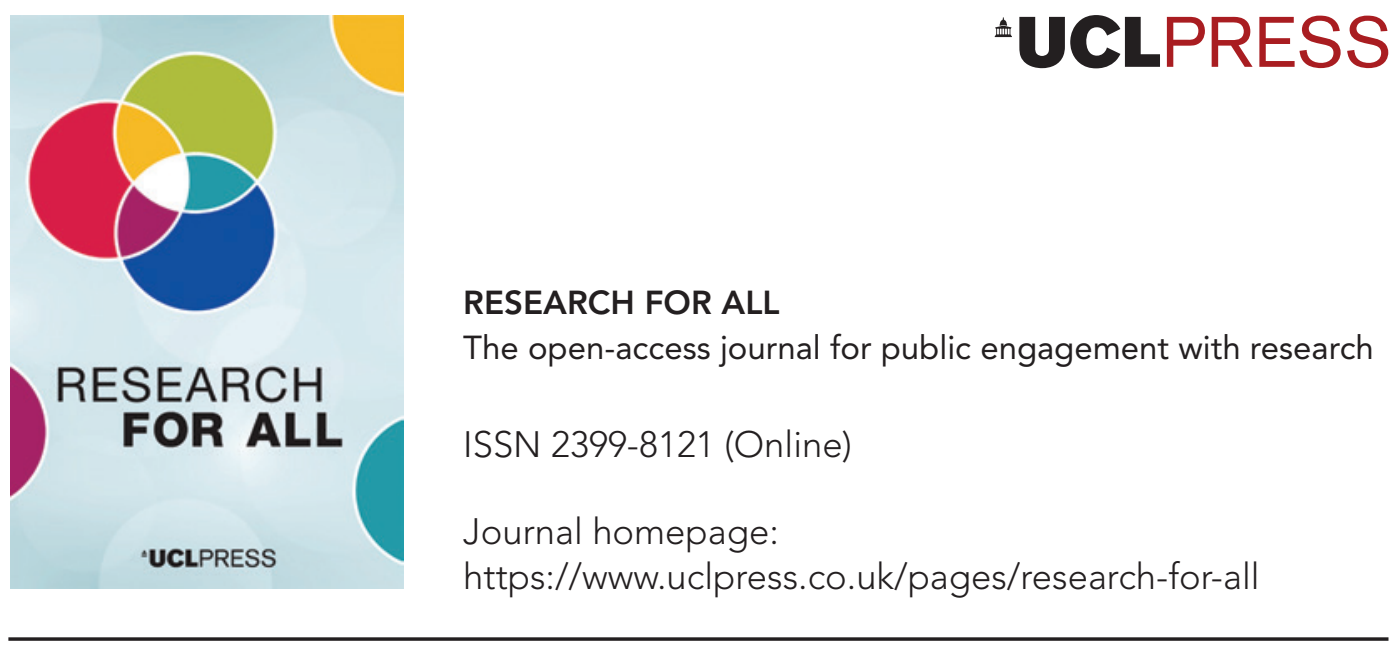

\title{
Who inspired my thinking? - The co-factor: conversation, collaboration, co-production
}

Joanna Verran (iD

\section{How to cite this article}

Verran, J. (2020) 'Who inspired my thinking? - The co-factor: conversation, collaboration, co-production'. Research for All, 4 (2), 310-13. Online. https://doi.org/10.14324/ RFA.04.2.12

Submission date: 7 October 2019

Acceptance date: 12 May 2020

Publication date: 22 September 2020

\section{Peer review}

This article has been through editorial review.

\section{Copyright}

(C) 2020 Verran. This is an open-access article distributed under the terms of the Creative Commons Attribution Licence (CC BY) 4.0 https://creativecommons.org/licenses/by/4.0/, which permits unrestricted use, distribution and reproduction in any medium, provided the original author and source are credited.

\section{Open access}

Research for All is a peer-reviewed open-access journal. 


\title{
Who inspired my thinking? - The co-factor: conversation, collaboration, co-production
}

\author{
Joanna Verran* - Manchester Metropolitan University, UK
}

I find it impossible to identify one public engagement, organization or population who has 'inspired my thinking'. Reflecting on my public engagement activities over the past 10-15 years, I know that without the partners I worked with, my thinking would have been much more limited, our events might have been non-existent, and they would have been less effective, less innovative - and far less fun! So, they have been my inspiration.

My research focuses on the interactions occurring between microorganisms and inert surfaces, so I collaborate with engineers, polymer chemists, physicists and so on. They know about the surfaces, and I know about the microorganisms, so we study the interactions together. Within the sciences, different approaches and terminologies are used, which often need clarification. One particular grumble was the loose usage of the term 'biofilm': microorganisms attached onto dry surfaces were unlikely to grow, whereas in the presence of nutrition and moisture, they can replicate to produce biofilm. I learnt to listen carefully to ensure that we were talking about the same mode of survival, since it would significantly affect any antimicrobial effect of a surface on the viability of attached cells. This also helped me to recognize my own lack of expertise in other subjects, and to avoid making assumptions.

Communication, then, has always been close to my heart. From the beginning of my teaching career, I encouraged my students to consider, and practise, disciplines such as art, design and history as a route for communicating microbiology, and for conversations and engagement with non-scientists - their families and friends, for example. This work led to collaborations with artists in a series of sci-art projects. I loved how artists used their notebooks to trigger and develop their ideas, and I encouraged my students to invest in and treasure their lab books in the same way. Questions from artists were so different from those I was used to ('Why don't all bacterial colonies look the same?'), and they were intrigued by changes in nomenclature of microorganisms that caused species to 'cease to exist', and thence in the concept of existence. These same issues face clinical microbiologists, where infections caused by newly (re)characterized genera lack a treatment history - even though the old name and behaviour of the pathogen might be familiar. Which name should be reported to the GP? What do they need to know? These challenging discussions helped me to realize that my fact-based approach to microbiology was perhaps not what nonmicrobiologists might find fascinating or useful. I tried to look at my science from more than my own relatively informed perspective, hoping to engender among my audiences a sense of wonder that would blend with engagement and enjoyment.

In the main, participants in my public engagement activities have comprised families or adult; it is likely there will be some underpinning interest in science to motivate them to come to events in the first place. However, nowadays I try to start planning from a different place, using hooks that might attract various audiences - for 
example, through co-creation of dining experiences, immersive theatre or events at literature festivals, so that 'the science' is not perceived to be didactic, patronizing, or for the benefit of the scientist.

Menus Made by Microbes began when an enthusiastic biomedical science undergraduate student came to talk about her final-year project idea, focusing on public engagement. She wanted to raise awareness of the human microbiome and probiotics. We talked about her aims, and then considered the intended audience, the nature of the event and its location, date and evaluation, and decided to utilize the Saturday Science events run at the Science and Industry Museum in Manchester, which provided a ready-made venue, date and family audience. We decided to focus on 'good bacteria', illustrated by the global use of fermented food. MetMUnch (www. metmunch.com), a social enterprise at Manchester Metropolitan University, is a student network that promotes sustainable and nutritious food. The MetMUnch academic lead joined our team, and some of her students participated in the event. Risk assessment, insurance, health and safety, hygiene and any ethical issues were addressed in advance of the event. Through MetMUnch's contacts, we obtained a range of fermented foods, and we devised a series of interactive events that would encourage audience engagement and support our evaluation. These activities included quizzes, videos, food tasting, and mapping the origin of different fermented foods. This popular and inclusive event generated so much adrenalin among our delivery team that we went on to design a series of eating experiences where microorganisms either produced the food or were the food. We worked with chefs, breweries, street food vendors and community groups to deliver four very different experiences - and published our findings. The Menus Made by Microbes template remains a useful vehicle for delivering enjoyable informal activities (eating, conversation) underpinned by science and collaboration (Verran et al., 2019).

I set up the Bad Bugs Book Club in 2009 (www2.mmu.ac.uk/engage/what-wedo/bad-bugs-bookclub/) because I was convinced that fiction provided a useful vehicle for discussion about science between adult scientists and non-scientists. The aim of the group is to discuss novels in which infectious disease forms part of the plot. Eleven years and about sixty books later, the website provides a useful resource of meeting reports and reading guides for other book clubs to use freely. Since the participants bring different perspectives to the meetings, learning is implicit for everyone. I learnt so much about creative writing - unreliable narrators, plot devices, story arcs - and through reading books from various genres and by various authors, I was able to experience different writing styles, identify those that I particularly enjoyed - and explain why. The fact that half of the original book club members remain in the group after a decade perhaps reveals that I am not alone in my new learning. We observed how fiction often followed fact, with real pandemics (particularly influenza) stimulating authors to write novels about these new outbreaks. We termed this 'emerging infectious literatures', to parallel the phenomenon of 'emerging infectious diseases'. Unfortunately, this could not be better illustrated than by the current coronavirus pandemic. Discussion (online via social media) allows us to consider what may or may not have been learnt in previous disease outbreaks, and allows us to engage with our feelings. No doubt coronavirus will figure in its own fiction in due course.

I was enchanted to uncover the infectious nature of zombies and vampires as presented in literature, and I worked with a colleague from the University Writing School to examine the rise of the zombie novel, and how more recently the zombie has acquired a predominantly infectious nature (Verran and Aldana Reyes, 2018). Zombies are particularly versatile models for engaging audiences of all ages with science, 
so our Monsters, Maths and Microbiology group was born, combining literature, microbiology and computer science. We use zombie fiction to identify, with our audiences, the parameters of a zombie outbreak, and then input these parameters into an outbreak simulation ('SimZombie'). The activities are designed to raise awareness of disease epidemiology, control and prevention. We designed pub quizzes, zombie training camps and other immersive events for festivals (Cheltenham Science Festival, Manchester Science Festival, Manchester Children's Book Festival, Manchester Gothic Festival), and were invited to participate in an immersive theatre event (www. deadinburgh.co.uk) where scientists advised the public how best to control a zombie outbreak. Clearly, zombies in particular provided a useful platform from which to engage with hundreds of people about infectious disease (Verran et al., 2014), as well as being a focus for exciting cross-disciplinary collaboration. This was one of the most interesting research projects of my career!

Perhaps because of the pressures on research scientists to publish their work in peer-reviewed journals, I have always tried to bring the same motivation to my education and public engagement research. Thus, any team working on the design and delivery of an event needs to think about what they are trying to do (aims/hypothesis), how to do it (methods), what observations to make (results), and their significance and effectiveness in terms of the original aims (discussion/conclusions). These initial conversations also tend to begin with 'why are we doing this?' It might be because an undergraduate student project demands it, or a science festival is imminent, or simply because it is timely (for example, antimicrobial resistance is an ongoing topic in microbiology engagement). However, for public engagement research, it is also important to know whether there are pre-existing perceptions, changes in attitudes, or evidence of engagement. This qualitative approach is different from quantitative methods, with which natural scientists are more familiar. Collaboration with social scientists, educators and postgraduate students, who, with me, needed to learn these techniques, has really enriched how I consider the effectiveness or impact of an event. We think how to design activities that relate to the aims (which makes us carefully consider the aims), and how to evaluate without intervention in the event itself (evaluation is not the focus of the audience, only of the delivery team). What is the long-term impact of the event on audience attitudes? How might this be assessed with due attention paid to privacy and any ethical issues? And so on.

In short, my career has been enriched throughout by collaboration, and by being open to new and different ways of communication. My philosophy of research, teaching and public engagement has derived from these collaborations. I have learnt the importance of research approaches to public engagement. We have developed public engagement activities that make science accessible, jargon-free, interactive, enjoyable and interesting through cross-disciplinary outputs. We are reliable, enthusiastic, organized and realistic - the 'co-factory'!

\section{Notes on the contributor}

Joanna Verran is Emeritus Professor of Microbiology at Manchester Metropolitan University, and a national teaching fellow. In addition to her laboratory-based research, she publishes on education and public engagement. She has worked on education and engagement activities with several microbiology societies, and established the Education and Public Engagement strand for the Federation of European Microbiology Societies. In 2019, she received the AAAS Mani L. Bhaumik Award for Public Engagement with Science. 


\section{References}

Verran, J. and Aldana Reyes, X. (2018) 'Emerging infectious literatures and the zombie condition'. Emerging Infectious Diseases, 24 (9), 1774-8. Online. https://doi.org/10.3201/eid2409.170658

Verran, J., Crossley, M., Carolan, K., Jacobs, N. and Amos, M. (2014) 'Monsters, microbiology and mathematics: The epidemiology of a zombie apocalypse'. Journal of Biological Education, 48 (2), 98-104. Online. https://doi.org/10.1080/00219266.2013.849283

Verran, J., Redfern, J., Moravej, H. and Adebola, Y. (2019) 'Refreshing the public appetite for "good bacteria": Menus made by microbes'. Journal of Biological Education, 53 (1), 34-46. Online. https://doi.org/10.1080/00219266.2017.1420678 